\title{
LEVANTAMENTO TURÍSTICO DO JARDIM BOTÂNICO DE LONDRINA
}

\author{
Edinéia Vilanova Grizio Orita ${ }^{1}$ \\ Carlos Alberto Hirata ${ }^{2}$ \\ Gabriel Merlini Tissiano ${ }^{3}$ \\ Patrícia Moreira Marques ${ }^{4}$
}

Resumo: O Jardim Botânico de Londrina, criado em dezembro de 2005, não possuía até a presente data um banco de dados com informações do perfil dos seus visitantes. Este trabalho teve por finalidade iniciar a construção desse banco, por meio de levantamento quantitativo e qualitativo, com o objetivo de avaliar com sugestões a funcionalidade da estrutura do Jardim Botânico, que, após tabulação e análise, sirvam de subsídios para sua gestão e administração. O método utilizado para o desenvolvimento da pesquisa foi coleta de dados in loco, por meio de aplicação de 720 questionários de entrevistas direta pessoal. A compilação e tabulação dos dados coletados foram realizadas no programa Windows Excel 2016 com 6.480 resultados quantitativos e 720 qualitativos apresentados na forma de porcentagem (gráficos) para um período de 12 meses.

Palavras-chave: Jardim Botânico; Perfil; Visitante; Educação Ambiental.

Abstract: The Botanical Garden of Londrina, created in December 2005, did not have a database with information on the profile of its visitors. The purpose of this work was to start the construction of this bank, through a quantitative and qualitative survey, with the objective of evaluating with suggestions the functionality of the Botanical Garden structure, which, after tabulation and analysis, serve as subsidies for its management and administration. The method used for the development of the research was data collection in loco, through the application of 720 questionnaires of direct personal interviews. The compilation and tabulation of the collected data was performed in the Windows Excel 2016 program with 6,480 quantitative and 720 qualitative results presented as a percentage (graphs) for a period of 12 months.

Keywords Botanical Garden; Profile; Visitor; Environmental Education.

\footnotetext{
${ }^{1}$ Profä. Dra. do Departamento de Geociências da Universidade Estadual de Londrina. E-mail: edineia@uel.br.http://lattes.cnpq.br/3741837265588407

2Profo. Dr. do Departamento de Geociências da Universidade Estadual de Londrina. E-mail: hiratauel@gmail.com. http://lattes.cnpq.br/7160286050619793

${ }^{3}$ Mestrando do Programa de Pós-Graduação em Geografia da Universidade Estadual de Londrina. E-mail: gtissiano@gmail.com. http://lattes.cnpq.br/7993278795153083

4 Engenheira Agrônoma do Jardim Botânico de Londrina, Secretaria Estadual de Meio Ambiente e Recursos Hídricos. E-mail: patrícia.moreira@sema.pr.gov.br. http://lattes.cnpq.br/2144923665540476
}

Revbea, São Paulo, V. 15, № 1: 150-159, 2020. 


\section{Introdução}

No transcorrer do ano de 2017 foram realizadas reuniões com os servidores e Gerente do Jardim Botânico de Londrina com o intuito de fazer o desenvolvimento de um planejamento estratégico para melhorar o atendimento aos visitantes do Jardim Botânico de Londrina. Durante as reuniões, verificouse a escassez de informações a respeito do perfil de seus visitantes, o que gerou a necessidade de desenvolver a presente pesquisa a fim de buscar conhecer o perfil dessas pessoas, analisar suas características e construir um banco de dados qualitativo e qualitativo para disponibilizar ao planejamento das atividades da administração do jardim uma ferramenta de gestão sustentável, além de verificar os fatores que influenciam as visitas ao Jardim Botânico de Londrina.

A importância dos Jardins Botânicos está relacionada ao auxilio, por meio da Educação, a construção da consciência ambiental na sociedade. Portanto, a pesquisa visou obter informações para auxiliar no seu monitoramento, vindo de encontro com as recomendações estabelecidas pelo Ministério do Meio Ambiente, por meio do Conselho Nacional de Meio Ambiente (CONAMA), resolução 266 artigo $7 \S 15$, onde define que os Jardins Botânicos devem auxiliar todas as Unidades de Conservação, do Sistema Nacional de Unidades de Conservação (SNUC), lei 9.985 de 18 de julho de 2000, através de suas ações no monitoramento de público.

As funções e o papel dos Jardins Botânicos na sociedade evoluíram ao longo do tempo. Segundo Krishnan e Novy (2016), os Jardins Botânicos eram originalmente utilizados para estudo de plantas medicinais em meados do século XVI. Eles se transformaram em ambientes ativos para introdução, cultivo e divulgação de culturas economicamente importantes durante a Europa expansão das colônias na Ásia, América e África durante os séculos XVII a XIX.

Durante a segunda metade do século $X X$ foi dada importância à necessidade de conservação e uso sustentável da biodiversidade (KRISHNAN; NOVY, 2016). No século XXI, os Jardins Botânicos são desafiados a abordarem questões que se estendem além das paredes do jardim, colocando a questão social e ambiental como missão.

Os Jardins Botânicos são espaços importantes para a conservação da flora. Normalmente se caracterizam como uma área delimitada em meio ao espaço urbano, destinada ao cultivo, manutenção, conservação e divulgação de informações sobre a vegetação. Essas áreas são um excelente ambiente para se desenvolver diferentes projetos e pesquisas, destacando a relevância da conservação ambiental nas diferentes áreas como educação, biologia, turismo, artes, história, entre outras, possibilitando a divulgação do conhecimento de espécies de plantas (ROCHA; CAVALHEIRO, 2001).

Inicialmente os jardins e hortos botânicos surgiram para o cultivo de plantas de interesse medicinal, e mais tarde para cultivar plantas de interesse 
comercial. Datados do século XVI, os Jardins Botânicos mais antigos do mundo tinham a sua história ligada às fundações de medicina e serviam para fornecer material para os alunos de medicina e farmácia na confecção de medicamentos (PEREIRA, 2006).

O Jardim Botânico de Londrina não possuía até a presente data, um banco de dados com informações do perfil dos seus visitantes. Esse trabalho teve por finalidade iniciar a construção de um banco do perfil dos visitantes, no qual foram aplicados 720 questionários de entrevistas direta com perguntas abertas e fechadas no período de junho de 2018 a maio de 2019. Os dados foram compilados, tabulados e apresentado os resultados quantitativos e qualitativos em gráficos por meio de porcentagem durante o período de 12 meses.

\section{Metodologia}

O procedimento de coletar dados referentes ao perfil do entrevistado é realizado com frequência em pesquisas voltadas ao planejamento turístico (Beni, 2004). Os aspectos socioeconômicos, culturais, educacionais, demográficos, entre outros, contribuem de maneira significativa nos resultados finais de pesquisas científicas (TVEIT, 2009).

Nesse sentido, o delineamento do perfil do usuário do Jardim Botânico de Londrina, foi traçado com base na coleta de dados in loco, por meio de aplicação de 720 questionários, adaptados do modelo proposto por Silva (2012), composto por perguntas relacionadas à idade, ao gênero, ao nível de escolaridade, a região geográfica de procedência dos visitantes e questões que permitiam ao entrevistado analisar e avaliar os serviços e equipamentos presentes no Jardim Botânico, inclusive sugerindo melhorias para o mesmo. Todos os entrevistados assinaram um Termo de Consentimento Livre e Esclarecido e a pesquisa foi autorizada pelo Comitê de Ética em pesquisa envolvendo seres humanos da Universidade de Londrina com o protocolo $\mathrm{N}$ 87252918.0.0000.5231 / parecer: 2.639.809.

Os questionários foram aplicados ao longo do ano vinculados ao prazo de vigência dessa pesquisa. As coletas foram distribuídas dessa maneira com o intuito de verificar se há significativas alterações no perfil dos visitantes.

Os dados foram complicados e tabulados no programa Windows Excel 2016 e os resultados foram apresentados em gráficos por meio de porcentagem.

\section{Resultados e Discussão}

O Jardim Botânico de Londrina é uma das mais importantes unidades de pesquisa e conservação de espécies nativas e exóticas no Paraná (Figura 1). Esse espaço é importante para à proteção e cultivo de espécies silvestres raras, ameaçadas de extinção e ecologicamente importantes para a restauração e reabilitação de ecossistemas (Figura 2). 


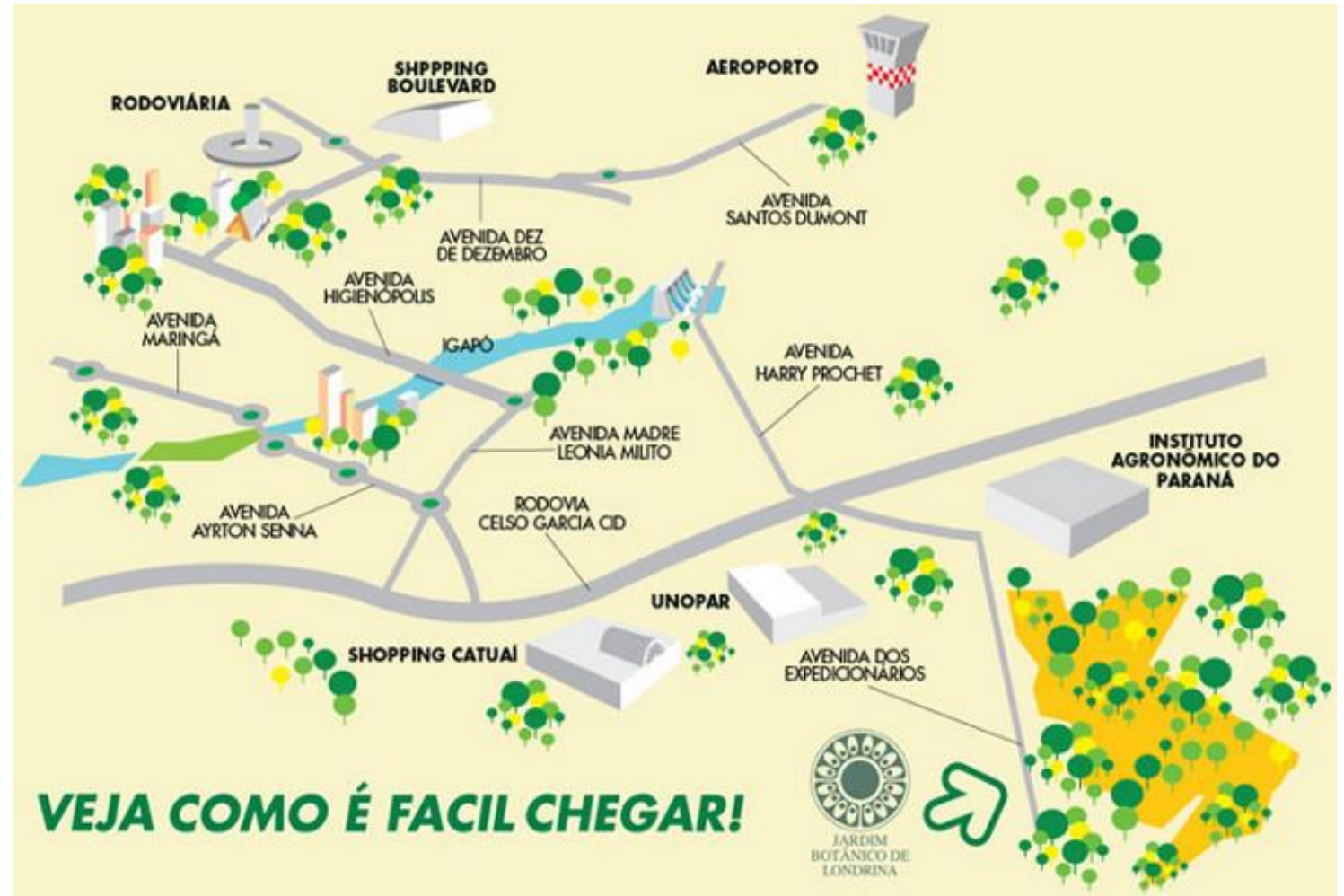

Figura 1: Localização do Jardim Botânico de Londrina.

Fonte: Secretaria do Meio Ambiente e Recursos Hídricos.

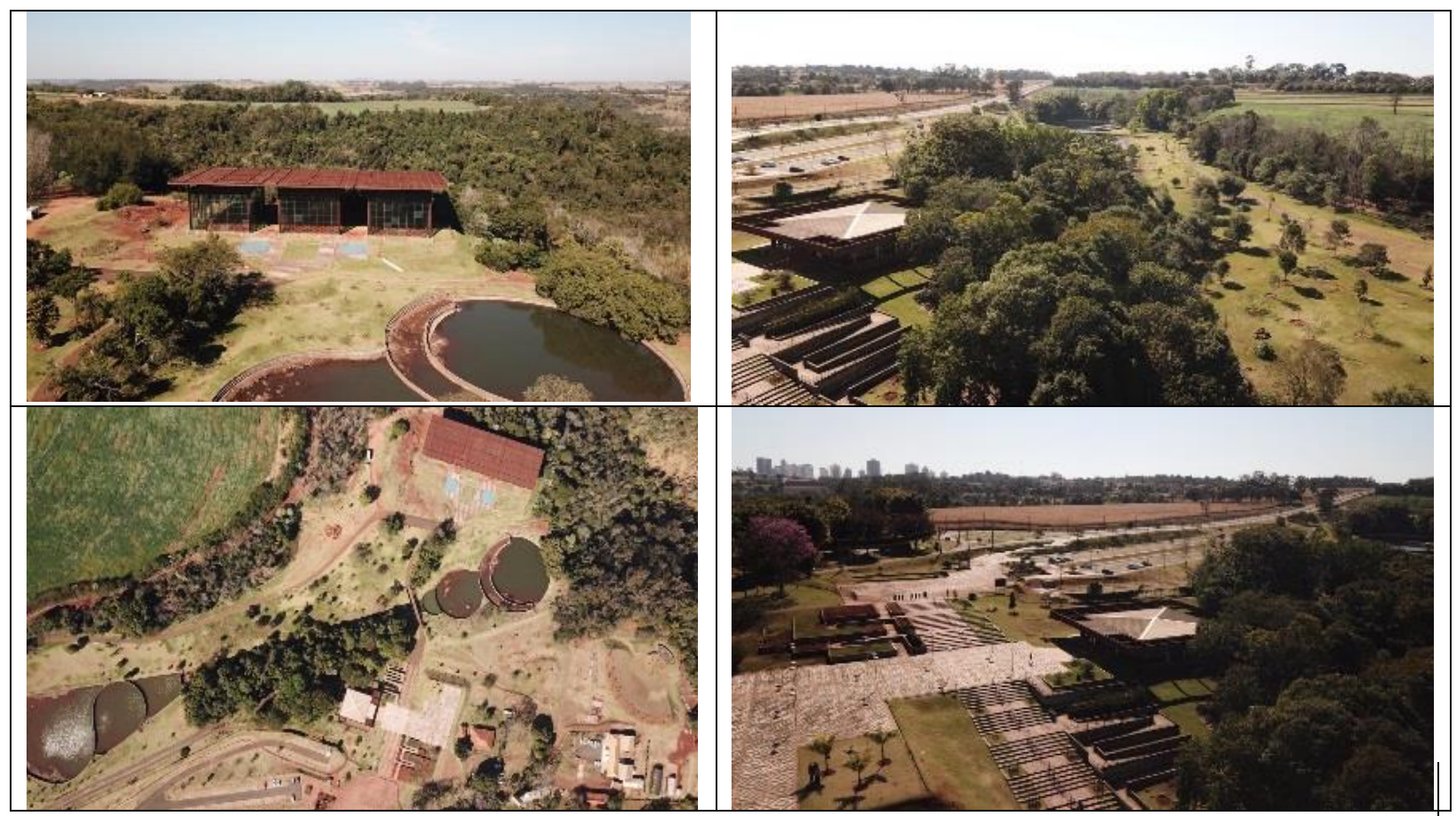

Figura 2: Jardim Botânico de Londrina.

Fonte: Matheus F. S. Hirata, 2019.

Revbea, São Paulo, V. 15, № 1: 150-159, 2020. 
A análise do perfil das pessoas que frequentam o Jardim Botânico de Londrina foi realizada a fim de fornecer uma ferramenta de avaliação dos serviços e equipamentos do Jardim Botânico de Londrina para subsidiar o aprimoramento dessa estrutura pública.

Foi utilizado um questionário de entrevista para conhecer o perfil dos visitantes, esse foi compilado num banco de dados no programa Windows Excel 2016, e após analisado.

Com essa compilação e tabulação dos questionários foi possível a construção desse banco de dados com 720 questionários com informações quantitativas e qualitativas coletadas no período de junho de 2018 a maio de 2019.

Os questionários demonstraram na análise do gênero, faixa etária e escolaridade uma predominância do gênero feminino, faixa etária de 19 a 30 anos e nível médio de escolaridade (Figura 3)

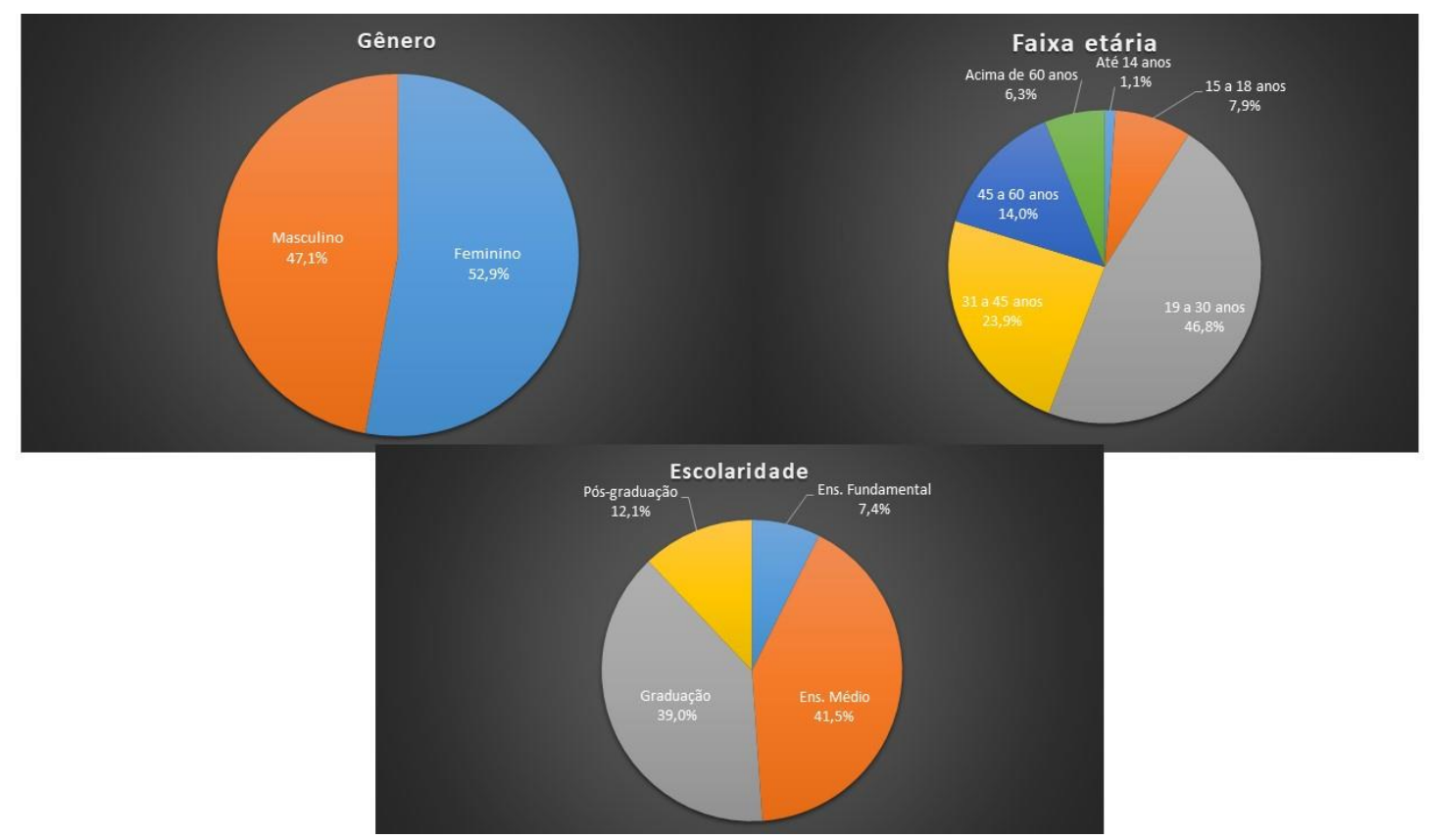

Figura 3: Gênero do entrevistado, faixa etária e grau de escolaridade.

Fonte: Organizado pelos autores.

No tocante aos aspectos quantitativos, nota-se que o visitante do Jardim Botânico de Londrina é predominantemente do Estado do Paraná, com predominância para a região oeste da cidade de Londrina, seguida da região sul (Figura 4). E 59,6\% dos visitantes informaram que permanece até 1 dia na cidade.

Há de se fazer destaque ao número de visitantes dos Estado da Bahia, Rio Grande do Sul, São Paulo e outros países como Estados Unidos, Itália e Paraguai. A diversidade da origem dos visitantes dá relevância e destaque aos idealizadores do Jardim Botânico de Londrina, que muito embora carece de maiores investimentos financeiros e de recursos humanos, o jardim tem de maneira satisfatória atingido alguns de seus objetivos. 


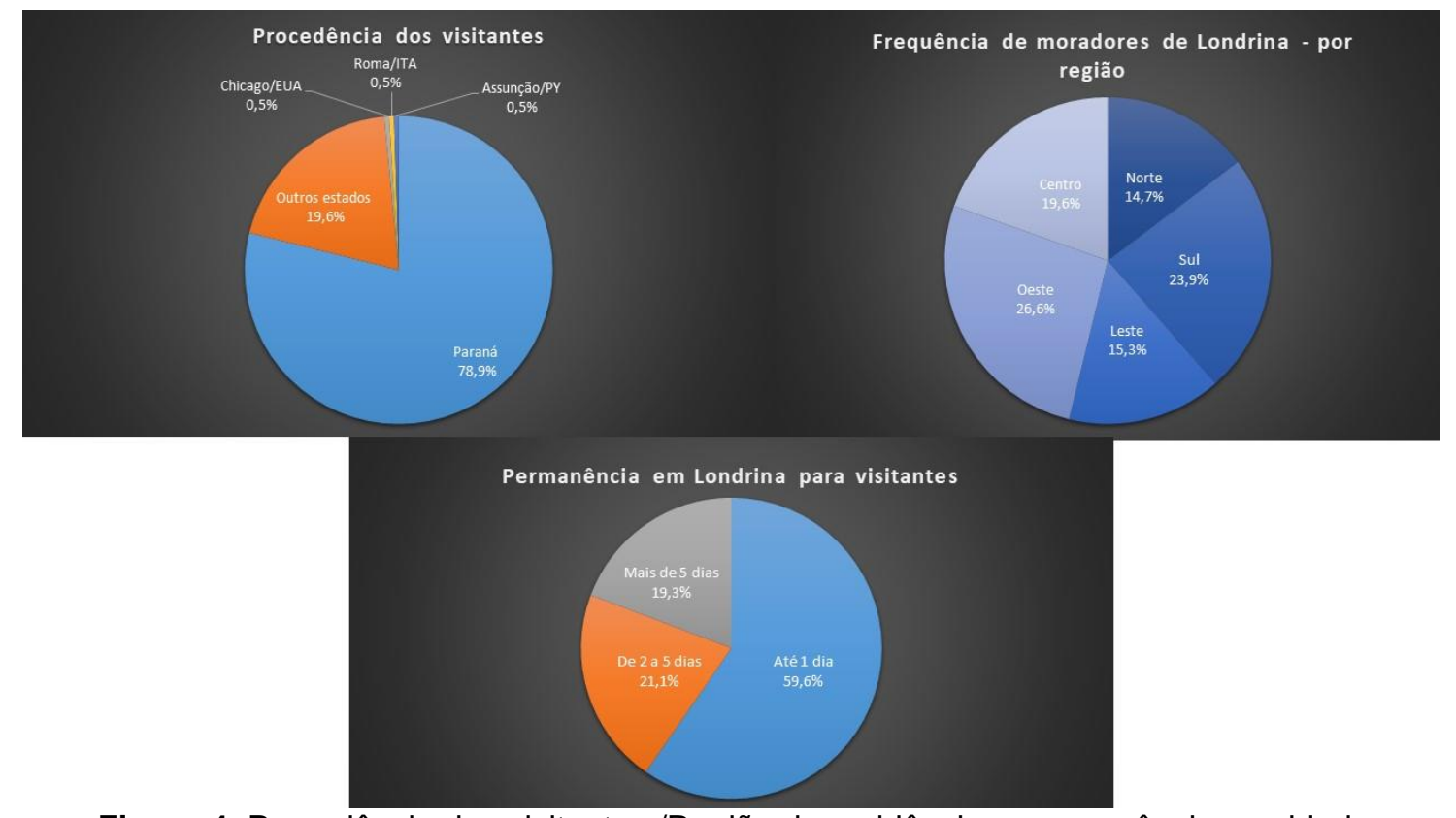

Figura 4: Procedência dos visitantes,/Região de residência e permanência na cidade.

Fonte: Organizado pelos autores.

O meio de transporte mais utilizado até o Jardim Botânico é o carro particular. É importante ressaltar que $11,3 \%$ utiliza ônibus coletivo (Figura 5). É de grande importância que haja estímulo para que mais pessoas utilizem desse transporte, contribuindo com o meio ambiente.

$\mathrm{Na}$ Figura 5 fica evidente que a motivação da visita ao local é predominantemente o lazer, seguida de pesquisa, turismo e outros. Esses valores confirmam a importância desse atrativo para a cidade de Londrina.

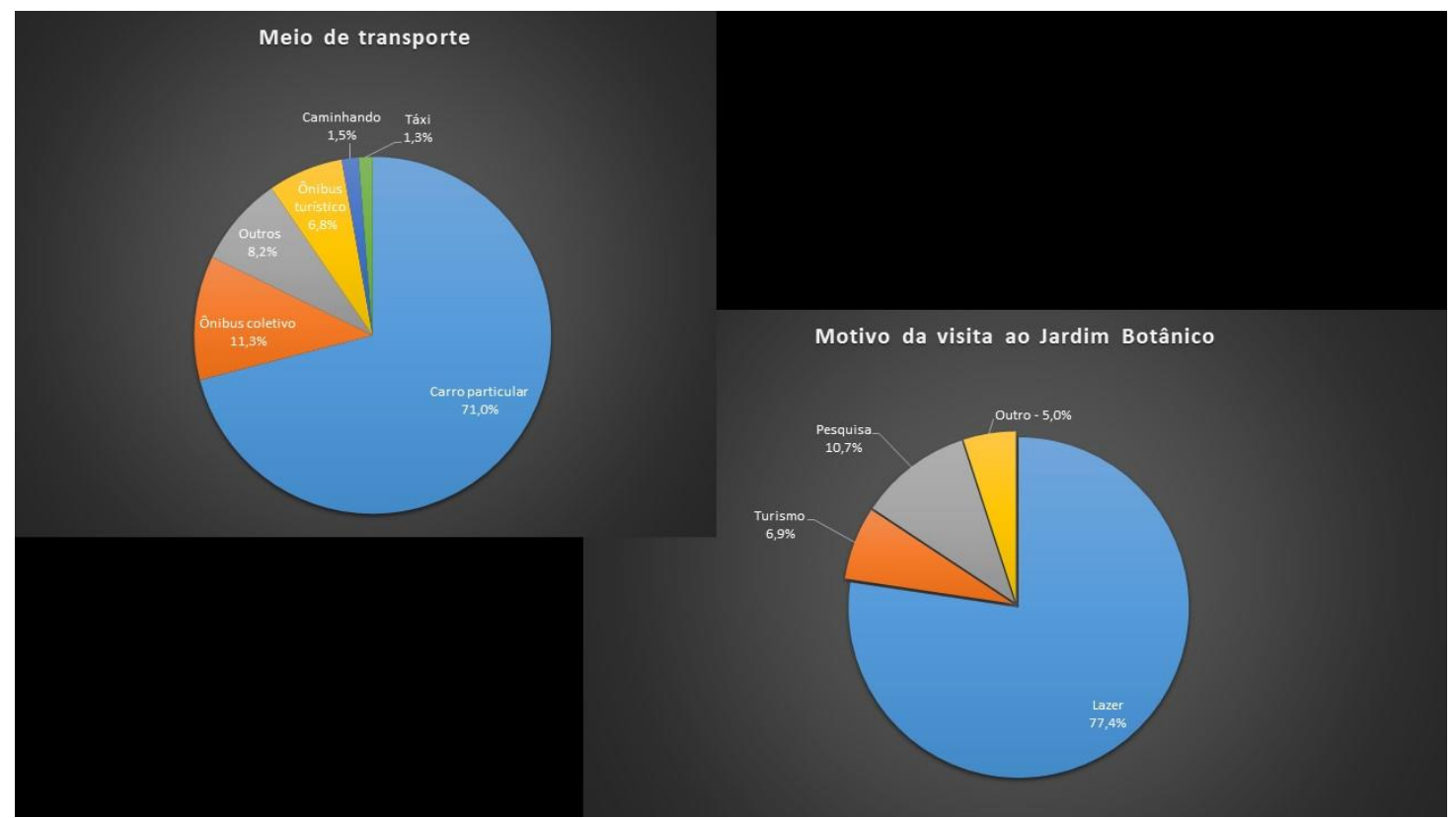

Figura 5: Meio de transporte e motivo de sua visita ao Jardim Botânico de Londrina.

Fonte: Organizado pelos autores.

Revbea, São Paulo, V. 15, № 1: 150-159, 2020.

revista brasileira

educação ambiental 
O planejamento turístico tem como função ordenar as ações humanas sobre uma localidade turística, direcionando a construção de equipamentos e facilidades visando evitar efeitos negativos nos recursos utilizados para fins turísticos, mantendo assim sua atratividade, por meio do planejamento e da conservação da paisagem (RUSCHMANN; WILDMER, 2000).

Para subsidiar a gestão dos atributos turísticos dentro do atrativo, foram perguntados aos visitantes quanto a suficiência de tais atributos. Mais de $50 \%$ dos respondentes afirmaram ter um atendimento satisfatório em relação aos bancos para sentar, as lixeiras, o estacionamento, sinalização, áreas de Educação Ambiental, bebedouros, informações turísticas e segurança (Figura $6)$.

Quanto ao banheiro, há apenas um químico em toda a extensão do Jardim Botânico de Londrina. 28,6\% dos visitantes deram sugestão de melhoria nos banheiros do jardim e enfatizaram a importância em verificar a possibilidade de serem implementados em outros locais do Jardim Botânico também. Essa sugestão também ocorreu para os bebedouros, onde $23,6 \%$ sugeriram a disponibilidade de bebedouros.

Em relação aos equipamentos e serviços, apesar do número expressivo daqueles que não observaram alguns itens abordados no questionário, foi possível concluir que o Jardim Botânico de Londrina forneceos de maneira suficiente para atender os visitantes e turistas. $95 \%$ dos visitantes (41,3\% satisfeitos e 53,7\% parcialmente satisfeitos) estão satisfeitos com a estrutura de equipamentos e serviços ali disponibilizados.

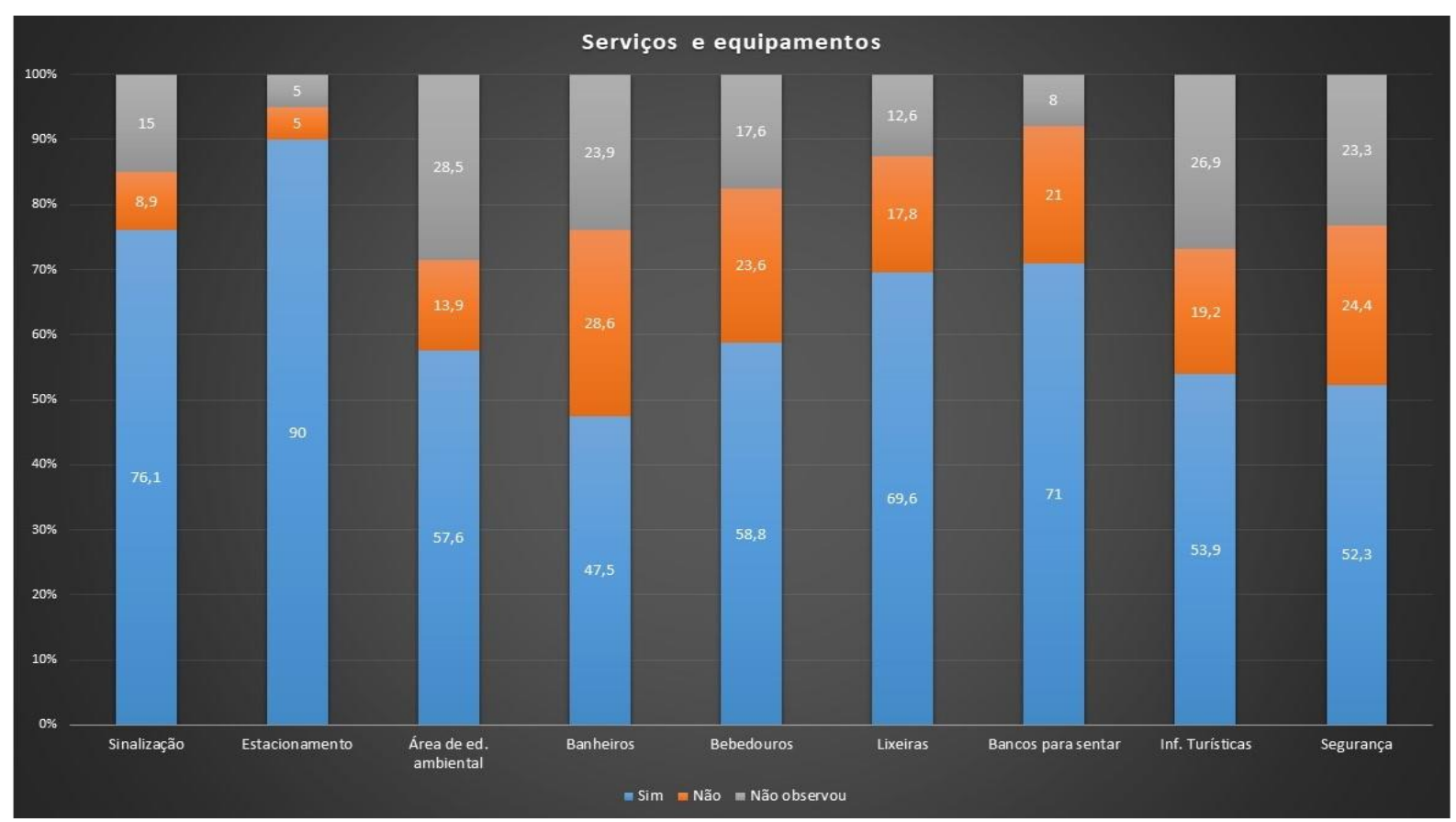

Figura 6: Quanto aos serviços e equipamentos instalados no Jardim Botânico de Londrina serem suficientes para atender os visitantes e turistas. Fonte: Organizado pelos autores. 
Os elementos citados na Figura 6 são fundamentais como apoio aos usuários de locais turísticos, pois são parte do planejamento turístico. Eles possuem o objetivo de proporcionar uma visitação agradável e, além disso, agregam valor aos atrativos (Andrade, 2006; Beni, 2004; Cooper, 2001).

Moraes (2008) constatou em sua análise sobre atrativos turísticos que o investimento em infraestrutura pode elevar o patamar de qualidade de um atrativo, criar uma expectativa de uma nova visita e a promover a indicação do local a terceiros.

Quanto a avaliação referente aos serviços e equipamentos em geral oferecidos aos visitantes do Jardim Botânico de Londrina, é possível verificar (Figura 7) que $53,7 \%$ dos visitantes e turistas estão parcialmente satisfeitos, $41,3 \%$ estão totalmente satisfeitos e $5,0 \%$ estão insatisfeitos.

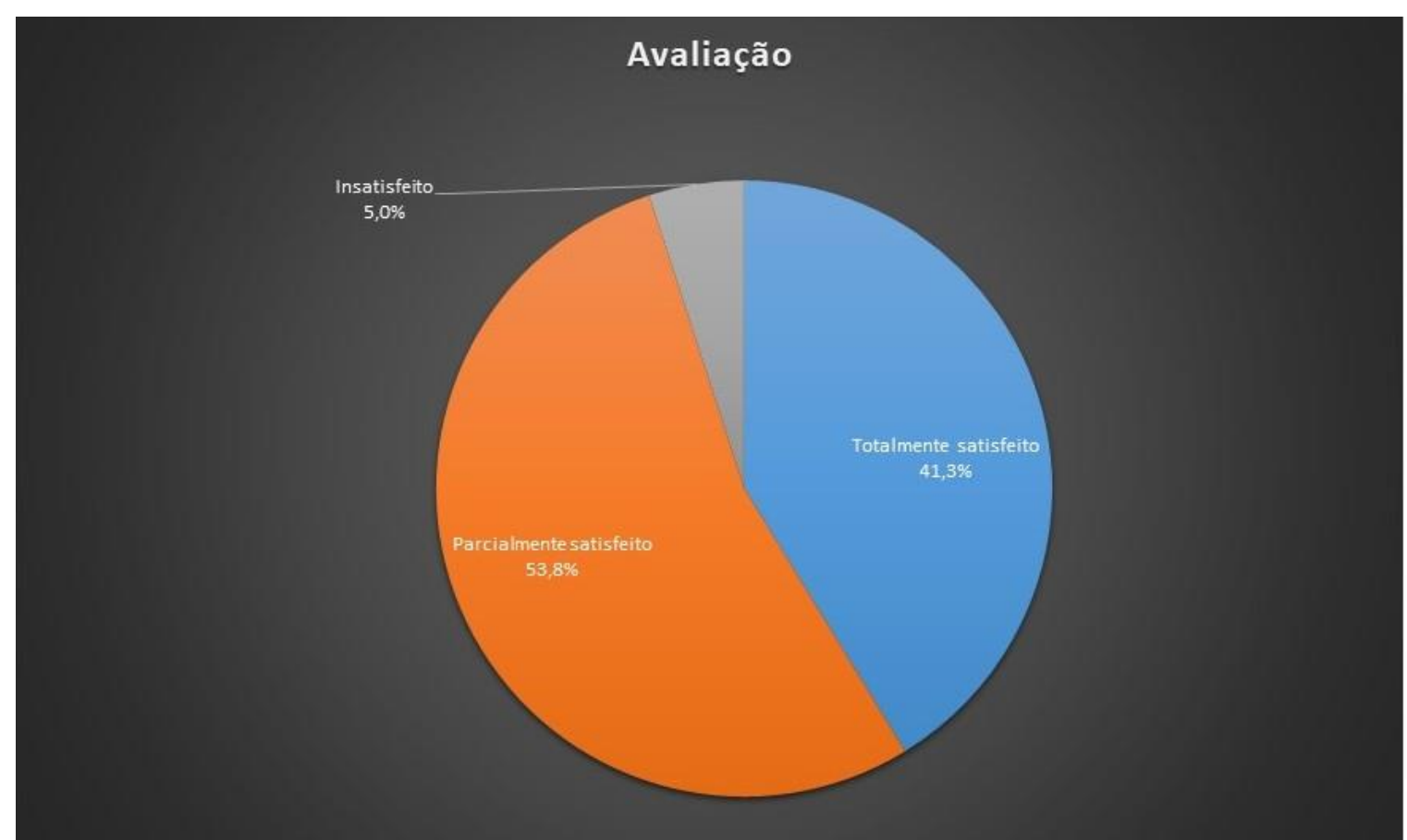

Figura 7: Avaliação quanto aos serviços e equipamentos em geral oferecidos aos visitantes do Jardim Botânico de Londrina. Fonte: Organizado pelos autores

O uso de método que leva em conta a percepção e sugestão dos usuários demonstrou ser uma boa ferramenta de gestão e pode servir de base para futuras investigações que visem aprimorar a qualidade dos atrativos turísticos (Figura 8). 


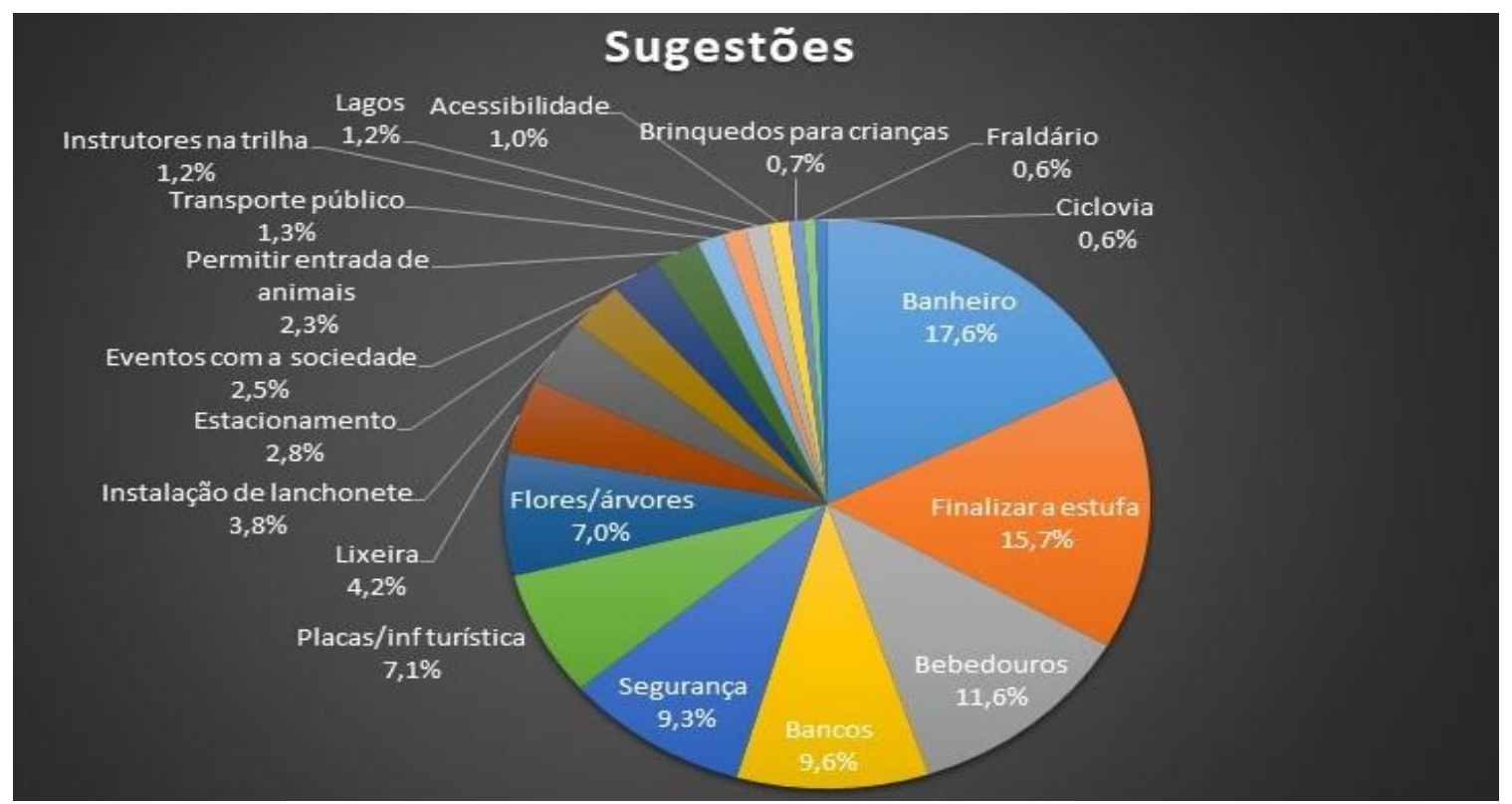

Figura 8 Sugestões e ideias para melhorias no Jardim Botânico de Londrina.

Fonte: Organizado pelos autores

Conforme já destacado por Luchiari (1998), a participação dos vários segmentos da sociedade e a mobilização desses vários grupos de interesse para debater e adequar o planejamento local é o que determina a força de um lugar.

\section{Considerações Finais}

O Jardim Botânico de Londrina oferece Educação Ambiental e lazer, difundindo a importância do equilíbrio entre homem e natureza. Esses pressupostos vêm de encontro com as finalidades de um Jardim Botânico, tais quais: promover a pesquisa, a conservação, a Educação Ambiental e o lazer compatível com a finalidade de propagar o valor multicultural das plantas e sua utilização sustentável.

Conhecer o perfil dos seus visitantes é de suma importância para que tais finalidades sejam atingidas, pois existem grandes desafios quando se fala de conservação e uso sustentável da biodiversidade no Brasil.

O levantamento turístico também é importante para planejar o uso desse bem público, onde o gestor deve acrescentar a essas expectativas um olhar panorâmico, observando as dinâmicas e os fluxos de deslocamento das pessoas nesse ambiente. Além disso, compreender o comportamento dos visitantes possibilita reduzir os impactos negativos de seu uso, assim como qualificar e expandir sua oferta de atividades.

É perceptível que o Jardim Botânico de Londrina cumpre um papel estratégico fundamental para a compreensão pública do ciclo conservaçãopropagação-Educação Ambiental. Um dia agradável vivido pelo visitante nesse espaço planejado pode ser a demonstração de que vale a pena participar da cultura do desenvolvimento sustentável. 


\section{Referências}

ANDRADE, J. V. Turismo Fundamentos e Dimensões. 8. ed. São Paulo, Ática, 2006.

BENI, M. C. Análise estrutural do turismo. 10. ed. São Paulo, Senac São Paulo, 2004.

COOPER, C.; FLETCHER, J.; WANHILL, S.; GILBERT, D.; SHEPHERD, R. (trad. Roberto Cataldo Costa). Turismo, Princípios e Práticas. 2. ed. Porto Alegre, Bookman, 2001.

KRISHNAN, S. \& NOVY, A. The role of botanic gardens in the twenty-first century. CAB Reviews 11, n. 023. 2016.

LUCHIARI, M. T. D. P. Urbanização turística. Um novo nexo entre o lugar e o mundo. In: LIMA, L. C. Da cidade ao campo. A diversidade do saber-fazer turístico. Fortaleza: UECE, 1998, p.15-29.

MORAES, A. V. Análise da Infraestrutura dos Atrativos Naturais do Município de Jardim. 60 f. Monografia (Graduação em Turismo). Universidade Estadual do Mato Grosso do Sul, Dourados, Mato Grosso do Sul, 2008.

PEREIRA, T. S. O Jardim Botânico ideal. Rede Brasileira de Jardins Botânicos. Rio de Janeiro. 128p. 2006.

ROCHA, Y.T.; CAVALHEIRO, F. Aspectos históricos do Jardim Botânico de São Paulo. Revista Brasileira de Botânica, v.24, n.15. 2001.

RUSCHMANN, D. V. M; WIDMER, G. M. Planejamento turístico. In: ANSARAH, M. G. R. (org.). Turismo como aprender como ensinar. São Paulo: Senac São Paulo, 2000, p. 65-86.

SILVA, R. R. S. Avaliação Paisagística e Turística do Jardim Botânico de Curitiba, Paraná, Brasil. 2012. Dissertação (Mestrado em Engenharia Florestal) -Universidade Federal de Curitiba, Curitiba, 2012.

SOUZA, M. J. L. Como pode o turismo contribuir para o desenvolvimento local? In: RODRIGUES, A. B. (org.). Turismo: desenvolvimento local. $3^{\text {a }}$ ed. São Paulo: HUCITEC, 2002. p. $17-22$.

TVEIT, M. S. Indicators of visual scale as predictors of landscape preference: a comparison between groups. Journal of Environmental Management, v. 90, n. 9, p. 2882-2888, 2009. 